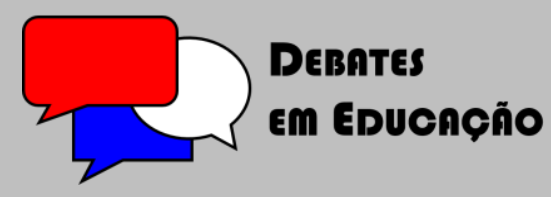

ISSN Eletrônico: 2175-6600

Vol. 10 | №. 20 | Jan./Abr. | Ano 2018

Elisângela Bastos de Mélo Espíndola

Universidade Federal Rural de Pernambuco

(UFRPE)

ebmespinndola@gmail.com

Licia de Souza Leão Maia

Universidade Federal de Pernambuco (UFPE)

limaia@ufpe.br

\section{DIFERENTES CENÁRIOS E REPRESENTAÇÕES DA COMPETÊNCIA PROFISSIONAL DOCENTE: O CASO DE PROFESSORES DE MATEMÁTICA BRASILEIROS E FRANCESES}

\section{RESUMO}

O objetivo deste trabalho é apresentar as representações sociais de professores brasileiros e franceses de sua competência profissional docente. O quadro teórico-metodológico da pesquisa está baseado na Teoria do Núcleo Central (ABRIC, 1976). O estudo foi organizado em três etapas: aplicação de teste de associação livre de palavras sobre competência para ensinar; hierarquização de itens; teste de verificação do núcleo central e entrevistas. Para tanto, contamos com a colaboração de 146 professores de matemática brasileiros e 136 professores franceses. Dentre os resultados, destacamos a competência profissional docente a partir de representações centradas em diferentes dimensões: cognitiva, afetivo-motivacional, ético-política e social.

Palavras-chave: Competência profissional docente. Representações sociais. Professores de matemática.

\section{DIFFERENT SCENARIOS AND REPRESENTATIONS OF THE TEACHER PROFESSIONAL COMPETENCE: THE CASE OF BRAZILIAN AND FRENCH MATH TEACHERS}

\begin{abstract}
The goal of this work is to introduce the social representations of Brazilian and French teachers of their teacher professional competence. The development theoretical and methodological of the research is based on Central Nuclear Theory (ABRIC, 1976). The study was organized in three steps: the application of an association test of free words about competence to teach; hierarchy of items; test of verification of the central nucleus and interviews. Therefore, we count on a collaboration of 146 math Brazilian teachers and 136 French teachers. Within the results, we highlight the teacher professional competence from the representations centered in different dimensions: cognitive, motivational and affective, ethical political and social.
\end{abstract}

Keywords: Teacher professional competence. Social representations. Math teachers.

Submetido em: 08/02/2017

Aceito em: 30/03/2018

DOI: $10.28998 / 2175-6600.2018 v 10 n 20 p 278$ 


\section{INTRODUÇÃO}

O presente estudo sobre o que pensam os professores de matemática brasileiros e franceses sobre sua competência profissional foi desenvolvido no seio de um projeto de pesquisa - de cooperação entre a Coordenação de Aperfeiçoamento de Pessoal de Nível Superior (CAPES) e o Comité Français d'Évaluation de la Coopération Universitaire avec le Brésil (COFECUB) - denominado: "Estudo do professor e de sua atividade matemática: concepções e recursos em e para sua atuação profissional". Particularmente, no eixo das representações sociais dos professores e de suas relações com o exercício da docência.

No campo educacional, consideramos que dentre as ideias que perpassam a noção de competência profissional, duas delas se destacam, como nos sugere Rios (2010): 1. A ideia de competência ligada à visão tecnicista, sendo que, falar em competência parece um pecado sem perdão e 2. A ideia de que competência é compartilhada e construída continuadamente. Sobre estas duas ideias, buscamos discorrer como a noção de competência se reveste de significados culturalmente e socialmente construídos; levandose em conta que uma das razões da variabilidade de significados desta noção é a diversidade dos contextos e dos campos de conhecimento em que ela é usada. Desta forma, tomamos como orientação teórico-metodológica deste estudo o referencial psicossocial da Teoria das Representações Sociais (MOSCOVICI, 1961) que tem em seu bojo uma forma de conhecimento usual, dito "senso comum" - entendido como "a forma que as pessoas cotidianamente formulam conceitos e proposições a partir da observação dos fatos diários e das informações que recebem" (ALMEIDA, 2005, p.185).

Ao longo deste trabalho são tecidas algumas considerações sobre o uso do vocábulo competência no cenário do Brasil e de outros países. Bem como, algumas diferenças, quanto ao seu uso no singular e no plural. Apresenta-se ainda como alguns autores (ex.: DEPRESBITERIS, 2001; SOUZA; PESTANA, 2009; LE BOTERF, 1998) têm discutido a noção de competência profissional a partir de diversas definições: conjunto de tarefas; conjunto de atributos; conjunto estruturado, holístico e integrado - a mobilização de recursos internos e externos. De outra forma, como certos autores têm buscado desvelar os seus componentes (cognitivo, emocional etc.) ou dimensões (técnica, estética etc.) (ex.: ALLAL, 2004; RIOS, 2010; LE BOTERF, 2011; WITTORSKI, 1998). Ademais, têm-se uma breve explanação sobre suas matrizes teórico-conceituais: condutivista; funcionalista; construtivista e crítico-emancipatória.

No que concerne ao uso da Teoria das Representações Sociais no quadro teóricometodológico do estudo, em particular, seguimos os pressupostos da abordagem estrutural 
ou Teoria do Núcleo Central (ABRIC, 1976) - a fim de discutirmos as semelhanças e diferenças entre os elementos centrais e periféricos do campo representacional dos professores brasileiros e franceses de sua competência profissional.

\section{COMPETÊNCIA PROFISSIONAL: DEFINIÇÕES E COMPONENTES}

\subsection{O vocábulo competência e seu uso no singular e no plural}

No Brasil, a título de exemplo, o vocábulo competência adquire diversos significados: "1. Faculdade que a lei concede a um funcionário, juiz ou tribunal para apreciar e julgar certos pleitos ou questões. 2. Capacidade, aptidão. 3. Alçada, jurisdição". (FERREIRA, 2002, p.168). “1. Atribuição, jurídica ou legal, de desempenhar certos encargos ou de apreciar ou julgar determinados assuntos. 2. Capacidade decorrente de profundo conhecimento sobre um assunto; aptidão" (LARROUSSE, 2002, p. 216).

Em outro cenário, no contexto inglês, Fleury e Fleury (2001, p. 184) apresentam que o dicionário Webster (1981, p. 63) define competência, como: "qualidade ou estado de ser funcionalmente adequado ou ter suficiente conhecimento, julgamento, habilidades ou força para uma determinada tarefa". Na França, a definição de competência no dicionário Le Robert (REY, 2006, p. 252) é apresentada da seguinte forma: “1. Conhecimento aprofundado, reconhecido, que confere o direito de julgar ou de decidir em certas matérias. Capacidade, qualidade/ cont. incompetência. 2. Aptidão legal, aptidão de uma jurisdição a instruir e julgar um processo. Atribuição, domínio [...]".

Segundo Ropé e Tanguy (1994, p.14), no Larousse Comercial (editado em 1930 na França) competência é "o conjunto de conhecimentos, qualidades, capacidades e aptidões que habilitam para a discussão, a consulta, a decisão de tudo o que concerne seu ofício [...]". Ela supõe conhecimentos fundamentados. Geralmente, considera-se que não há competência total se os conhecimentos teóricos não forem acompanhados das qualidades e da capacidade que permitem executar as decisões sugeridas.

Para Rios (2002, p.151), o que se constata no uso da palavra competência no singular, é uma espécie de alargamento da extensão do termo para "designar uma multiplicidade de objetos/ conceitos"; enquanto, quando é utilizada no plural, "algumas vezes substitui, isto é, toma o lugar de 'saberes', 'habilidades', 'capacidades', que designam elementos que devem estar presentes na formação e na prática profissional dos profissionais de educação". Nesta direção, Rovai (2010, p.17), coloca que o termo no plural - competências - é empregado para "designar os conteúdos específicos de cada 
qualificação ocupacional”; enquanto no singular, competência designa um conjunto de qualidades a serem desenvolvidas pela pessoa em "seu processo de formação profissional, fruto de interações entre uma estrutura bem organizada de conhecimentos e a experiência prática, que a capacita a agir com criatividade diante de situações-problema inusitadas, na área de sua especialidade".

\subsection{A competência profissional definida à luz de seus componentes e dimensões}

No campo educacional, como em outros campos, difundem-se três ordens de definições em torno da noção de competência profissional: conjunto de tarefas, conjunto de atributos e conjunto estruturado, holístico e integrado.

- Um conjunto de tarefas - supõe "tarefas independentes (saber fazer) e que se apresentam bem detalhadas. Sem interesse pelas relações que existem entre elas, a competência é analisada pela observação direta do desempenho" (SOUZA; PESTANA, 2009, p.145).

- Um conjunto de atributos - põem em cena os atributos gerais indispensáveis para o desempenho efetivo de profissionais. Para Depresbiteris (2001): os conhecimentos, práticas e atitudes. Segundo Souza e Pestana (2009): o saber, o saber-fazer e o saber ser. No entanto, desconsidera-se o contexto em que as competências são aplicadas.

- Um conjunto estruturado, holístico e integrado - combina a perspectiva de um conjunto de atributos com o "contexto". Leva-se em conta que "a competência é relacional, é uma combinação complexa de atributos (conhecimentos, atitudes, valores e habilidades) necessários para o desempenho profissional em situações específicas" (SOUZA; PESTANA, 2009, p.145).

Dentre as diferentes composições supramencionadas, a que se refere à competência profissional como um conjunto estruturado, holístico e integrado, tem sido relacionada à mobilização de recursos: internos e externos. Os recursos internos concebidos como aqueles de ordem pessoal, incorporados ao profissional. Como explica Perrenoud (2000, p.28): "as informações, saberes, esquemas, capacidades, competências mais específicas, mas também posturas, normas, valores e atitudes". Compreende-se que sem tais recursos, não existiria competência. Sobre os recursos externos, estes são aqueles de ordem externa aos sujeitos, de modo objetivo. Eles podem ser constituídos de 
máquinas, instalações materiais, informações, redes relacionais (LE BOTERF, 1998). Discute-se que o profissional não é competente sozinho; "ele é competente com seus bancos de dados, suas ferramentas de trabalho, seus colegas, os experts que ele pode consultar, suas redes de recursos, seus equipamentos, a rede de clientela, seus suportes institucionais" (ibidem, p. 134).

Segundo Le Boterf (2000, p.17), para agir com competência, "uma pessoa deve cada vez mais combinar e mobilizar não somente seus próprios recursos (conhecimentos, saberfazer, qualidades [...]), mas igualmente os recursos de seu meio: redes profissionais, redes de documentos, banco de dados [...]". Neste sentido, a competência não é uma soma ou uma simples adição de recursos; nem também a competência se reduz aos recursos. Uma competência pressupõe a existência de recursos mobilizáveis, mas não se confunde com os mesmos (LE BOTERF, 2011). Como explicam Ramalho et al. (2004, p. 76) "uma competência não é um saber, um savoir-faire, nem uma atitude, mas ela se manifesta quando um ator utiliza estes recursos para agir em um contexto".

Afirmam Ramalho et al. (2004, p. 75) que qualquer competência, por mais simples que seja, "constitui-se numa totalidade de diversas e complexas dimensões. Uma pessoa não tem uma competência técnica isolada das dimensões social, política, ética, etc." A título de exemplo, Rios (2010, p.159), apresenta quatro dimensões:

\footnotetext{
- a dimensão técnica, que diz respeito ao domínio dos saberes (conteúdos e técnicas) necessários para a intervenção em cada área específica de trabalho e à habilidade de construí-los e reconstruí-los;

- a dimensão estética, que diz respeito à tomada de consciência do aspecto relacional do trabalho e à presença da sensibilidade no âmbito do trabalho e sua orientação numa perspectiva criadora;

- a dimensão política, que diz respeito à consciência e à definição da participação na construção coletiva da sociedade e ao exercício de direitos e deveres;

- a dimensão ética, que diz respeito à orientação da ação, fundada nos princípios do respeito, da solidariedade e da justiça, na direção da realização de um bem coletivo.
}

De acordo com Rios (2010, p. 159), a dimensão técnica é suporte da ação competente. Sua significação, entretanto, é garantida somente na articulação com as demais dimensões - não é qualquer fazer que pode ser chamado de competente. "É importante considerar-se o saber, o fazer e o dever como elementos historicamente situados, construídos pelos sujeitos em sua práxis".

Em consonância com esta ideia multidimensional da competência profissional, Le Boterf (2011, p.82), descreve quatro referências para o profissional agir com competência: emocional, cognitiva, das regras profissionais e éticas. A referência emocional ocorre devido aos estados emocionais enviarem ao cérebro sinais de alarme e de encorajamento. 
A referência cognitiva concerne "ao raciocínio e às operações intelectuais solicitadas para o agir". No caso das regras profissionais estas ocorrem "em função das regras particulares ao coletivo de trabalho à qual pertence o profissional". Por fim, a referência ética diz respeito "aos valores que orientam as decisões, os modos de agir, os meios a utilizar para atingir os resultados".

Allal (2004, p. 83), define competência como "uma rede integradora e funcional construída por componentes cognitivos, afetivos, sociais, sensório-motores, capaz de serem mobilizados em ações finalizadas diante de uma família de situações”. Os componentes cognitivos correspondem às categorias de conhecimentos (declarativossaberes; procedimentais (saber-fazer); contextuais) e metaconhecimentos e regulações metacognitivas. Os componentes afetivos correspondem às atitudes e motivações. Os componentes sociais às interações, negociações [...] e os componentes sensório-motores à coordenação gestual.

A competência é apresentada, por Wittorski (2004), na interação de cinco componentes: cognitivo, afetivo, cultural, social e praxeológico. O componente cognitivo é constituído de dois elementos: um das representações cognitivas e os esquemas e teorias implícitos e outro, a representação que o autor faz da situação. O componente afetivo é entendido como um dos motores da competência. Ele reagrupa três elementos: a imagem de si, que pode ser valorizada ou desvalorizada, o investimento afetivo na ação, ou seja, o fato de viver com prazer ou sofrimento aquilo que se faz; e o engajamento, ou seja, a motivação. O componente cultural da competência corresponde ao modo pelo qual a cultura da organização na qual se situa o indivíduo ou o grupo autor da competência vai imprimir de certa forma às competências produzidas (WITTORSKI, 1998, p. 61). Em relação ao componente social, ele compreende ao mesmo tempo o reconhecimento efetivo pelo meio imediato (nível meso) ou da organização (nível macro ou societal) da prática do indivíduo ou do grupo. Finalmente, o componente praxeológico nos remete ao aspecto visível da competência, isto é a prática do qual o produto (desempenho) é objeto de uma avalição social. Trata-se de fato da parte visível, observável da competência.

Dentre as diferentes dimensões da noção de competência profissional, aqui apresentadas, aquelas de ordem "cognitiva, ético-política, social e afetivo-motivacional" suscitam serem as mais recorrentes; respectivamente, relacionadas a diversos tipos de "conhecimentos, capacidades, atitudes, afeições e/ou motivações e qualidades subjetivas e/ou traços da personalidade". O que de certa forma, para nós, corrobora com o estudo sobre a competência profissional docente à luz da TRS. Haja vista, que as RS devem ser estudadas articulando "os elementos afetivos, mentais e sociais e integrando - ao lado da 
cognição, da linguagem e da comunicação - a consideração das relações sociais que afetam as representações e a realidade material, social e ideativa sobre a qual elas têm de intervir" (JODELET, 2001, p. 75).

Tal fato, leva-nos a pensar a noção de competência profissional numa perspectiva crítico-emancipatória (como explicitamos a seguir); na medida em que buscamos dar voz aos professores, sobre representações engendradas em seu próprio grupo profissional; favorecendo assim, o desvelamento de elementos de sua profissionalidade docente. Pois, como afirma Sacristán (1999) a essência da profissionalidade docente reside na relação dialética entre tudo o que, através do professor, se pode difundir - conhecimentos, destrezas profissionais, etc. - e os diferentes contextos práticos.

\section{MATRIZES TEÓRICO-CONCEITUAIS QUE PERPASSAM A NOÇÃO DE COMPETÊNCIA PROFISSIONAL}

No campo educacional, vários autores, a exemplo de Deluiz (2001), Souza; Pestana, 2009; Marinho-Araújo; Rabelo, 2015, tratam a noção de competência profissional, à luz dos seguintes pressupostos teórico-conceituais: condutivista, funcionalista, construtivista e crítico-emancipatória.

Sobre a matriz condutivista, a competência é relacionada a uma série de savoir-faire. Como vimos, a um conjunto de tarefas. O que a faz ser relacionada, de um lado, ao behaviorismo, traduzida numa perspectiva fortemente articulada com o desempenho (PIRES, 2002). Por outro lado, esta matriz é relacionada aos modelos tayloristas e fordistas de organização do trabalho, pelos quais, um agente competente para uma tarefa é aquele que sabe executar e produzir o resultado desejado. As tarefas não sendo outra coisa, senão a lista de operações que o trabalhador deve realizar. Sobre esta concepção sublinhamos os perigos de reduzir as competências profissionais aos conhecimentos técnicos da tarefa; ou ainda somente à prática de procedimentos, ao simples saber-fazer.

Na matriz funcionalista, o foco da competência também é o resultado esperado (SOUZA; PESTANA, 2009, p.143). A competência é algo que "uma pessoa deve fazer ou deveria estar em condições de fazer; ou seja, são descritos produtos e não processos". Segundo Deluiz (2001), esta matriz tem sua base no pensamento sociológico funcionalista e seu fundamento metodológico-técnico é a Teoria dos Sistemas Sociais (aplicada à Administração) ${ }^{1}$. Nesta perspectiva, os objetivos e funções da empresa devem ser

\footnotetext{
${ }^{1}$ Propõe-se a análise não somente de um sistema em si, mas a relação entre o sistema e seu entorno.
} 
formulados em termos de sua relação com o ambiente externo, isto é, com o Mercado, a tecnologia, e as relações sociais e institucionais. Como consequência, a função de cada trabalhador na organização deve ser entendida em sua relação com o entorno da empresa e com os subsistemas dentro da empresa.

A Organização Internacional do Trabalho (OIT) (2002, p. 104), entende a referida perspectiva funcional, como uma técnica de análise para elaborar normas ou padrões de competência profissional inerente a uma função produtiva. Neste caso, "recomenda-se redigir funções em termos de resultados de desempenho e não simplesmente redigir tarefas e operações". Na matriz funcionalista, ao invés da análise se centrar nas tarefas a serem cumpridas (como na matriz condutivista), foca-se a função estratégica da empresa e os respectivos resultados esperados da atuação dos trabalhadores.

Deluiz (2001), discute que as críticas sobre as matrizes condutivista e funcionalista, referem-se ao fato de que as tarefas ou funções especificadas e detalhadas, por elas, acabam se convertendo nas próprias competências, que seriam visíveis a partir da observação direta do desempenho. No campo da Educação, grosso modo, um dos efeitos das matrizes supracitadas, pode ser entendido, como a formulação de objetivos de ensino; o que remete a mecanismos de controle relacionados às tarefas ou funções docentes e discentes. Haja vista, por exemplo, a expansão dos critérios de Avaliação Educacional em larga escala (baseados em competências) e as políticas públicas, voltadas ao gerenciamento estratégico de metas sobre os resultados escolares.

De outro modo, a matriz construtivista e a crítico-emancipatória são identificadas como propostas alternativas às matrizes condutivista e funcionalista. A definição de competência, na matriz construtivista, considera o sujeito, a ação do sujeito e suas relações contextuais. "Essa visão contrasta fortemente com aquela em que a aprendizagem ocorre pela transmissão passiva da informação de um indivíduo para outro e em que a chave que aciona a aprendizagem é a recepção e não a construção" (OIT, 2002, p.81). As normas ou padrões de competências não são vistas como metas absolutas, mas como construtos, que estão sujeitos a constantes mudanças, revisões e negociações. Portanto, a estratégia de melhoria contínua é a que melhor se adapta às propostas construtivistas. Neste caso, a competência profissional não deve ser entendida como um conjunto de tarefas ou de habilidades, atitudes, conhecimentos ou destrezas, já que "um conjunto de" não constitui por si só uma competência. E sim, na linha do que apresentamos sobre esta ser um conjunto estruturado, holístico e integrado. Um por em prática por uma pessoa em situação, em um contexto determinado, de um conjunto diversificado, mas coordenado de recursos (JONNAERT et al., 2005). 
Particularmente, sobre a matriz construtivista da noção de competência profissional, destacamos os estudos desenvolvidos no campo da Didática Profissional (que conjuga Psicologia do Desenvolvimento, Ergonomia Cognitiva e Didática). Podemos afirmar que uma das teorias de destaque neste domínio se refere à Teoria dos Campos Conceituais (TCC), definida por Vergnaud (1990, p.135) como: "uma teoria cognitivista que visa a fornecer um quadro coerente e alguns princípios para o estudo do desenvolvimento e da aprendizagem de competências complexas, notadamente àquelas que relevam das ciências e das técnicas". Na TCC se faz menção aos processos cognitivos e as respostas do sujeito em função das situações as quais ele é confrontado. Vergnaud distingue dois tipos de classes de situações:

1. As classes de situações por as quais o sujeito dispõe em seu repertório, a um dado momento de seu desenvolvimento e sob certas circunstâncias, as competências necessárias ao tratamento relativamente imediato da situação;

2. As classes de situações por as quais o sujeito não dispõe de todas as competências necessárias, o que o obriga a um tempo de reflexão e exploração, à hesitações, à tentativas frustradas, e o conduz eventualmente ao êxito, eventualmente ao fracasso (VERGNAUD, 1990, p.136).

Essencialmente, leva-se em conta extrair a estrutura conceitual de uma situação profissional e tentar inferir, a partir desta estrutura, as grandes classes de situações que vão gerar cada uma um repertório de regras de ação (PASTRÉ, 2007). Em relação às competências, destaca-se que existe um duplo movimento: "a competência se ajusta a uma nova situação, mas em retorno ela vai pulsar o ajustamento da situação a esta nova competência" (idem, p.13). A noção de situação é aquela no contexto do trabalho. Para as situações de trabalho em sua totalidade e dimensões, utiliza-se a análise ergonômica que tem como fio condutor a atividade - o fazer do trabalhador inserido em um contexto real, objetivando apreender o trabalho efetivamente realizado, nem sempre condizente com o trabalho prescrito.

Para Deluiz (2001), a matriz construtivista apresenta pontos de positividade ao atribuir importância às potencialidades do trabalhador e ao seu processo de aprendizagem. No campo educacional, podemos dizer que um dos efeitos, mais evidentes da matriz construtivista, é de fato, esta ênfase mais no processo de aprendizagem (discente e/ou docente) do que no produto. Onde a ideia de aprendizagem construída envolve duas noções importantes. A primeira é a de que os aprendizes constroem novos entendimentos, usando o que eles já sabem. A outra é a de que a aprendizagem é ativa em vez de passiva. Contudo, uma das críticas sobre a matriz construtivista é que esta não dá conta de uma concepção mais ampliada da noção de competência; haja vista, a necessidade de se 
ampliar o debate sobre a dimensão sociopolítica em que esta se insere. Desta forma, a matriz crítico-emancipatória busca envolver facetas que vão do individual ao sociocultural, situacional (contextual-organizacional) e processual (MARINHO-ARAÚJO; RABELO, 2015).

Na matriz crítico-emancipatória, a noção de competência profissional engloba:

Não só a dimensão individual, de caráter cognitivo, relativa aos processos de aquisição e construção de conhecimentos produzidos pelos sujeitos diante das demandas das situações concretas de trabalho, mas envolve uma outra dimensão: a de ser uma construção balizada por parâmetros socioculturais e históricos. A noção de competência está, assim, situada e referida aos contextos, espaços e tempos socioculturais e ancorada em dimensões macrosocioculturais de classe social, gênero, etnias, grupos geracionais, entre outras (DELUIZ, 2001, p.1).

Conforme Deluiz (2001), a identificação, definição e construção de competências profissionais na matriz crítico-emancipatória não se pauta pelas necessidades e demandas estritas do Mercado. Mas, leva em conta, a dinâmica e as contradições do mundo do trabalho, os contextos macroeconômicos e políticos, as transformações técnicas e organizacionais, os impactos socioambientais, os saberes do trabalho, os laços coletivos e de solidariedade, os valores e as lutas dos trabalhadores. De modo que se investigam as competências no mundo do trabalho a partir dos próprios trabalhadores; identificando os seus saberes formais e informais, suas formas de cultura e o patrimônio de recursos por eles acumulado na atividade profissional. A aprendizagem dos saberes disciplinares é acompanhada da aprendizagem dos saberes gerados nas atividades de trabalho: conhecimentos, valores, histórias e saberes da experiência.

Têm-se então, uma ideia de competência profissional que não é somente técnica, pois ela está ligada a todo um patrimônio de experiências coletivas, animada pela consciência dos trabalhadores, articulando sua dimensão profissional com a dimensão sociopolítica. Deluiz (2001, p.1) explica que a matriz crítico-emancipatória:

\footnotetext{
Atribui enorme importância à dimensão social da construção do conhecimento, entendendo a relação entre os homens e dos homens com o mundo como fundamentais para o desenvolvimento cognitivo e a aprendizagem. Busca, assim, construir competências para uma ação autônoma e capaz nos espaços produtivos, mas, igualmente, voltada para o desenvolvimento de princípios universalistas igualdade de direitos, justiça social, solidariedade e ética - no mundo do trabalho e da cidadania.
}

No campo da Educação, os efeitos da matriz crítico-emancipatória, de acordo com Deluiz (2001), Marinho-Araújo; Rabelo (2015) entre outros, ainda está em construção e objetiva ressignificar a noção de competência, de forma que atenda aos interesses do grupo 
profissional docente. É nesta perspectiva, que nos interessamos em discutir: o que pensam os professores, em particular de matemática ${ }^{2}$, sobre sua própria competência profissional? De que forma isto se revela no contexto educacional brasileiro e francês? Para tanto, propomos um estudo assentado na Teoria das Representações Sociais (TRS), no intento de conjugar, ao mesmo tempo, uma abordagem psicológica e social da noção de competência profissional docente.

\section{A TEORIA DAS REPRESENTAÇÕES SOCIAIS E A TEORIA DO NÚCLEO CENTRAL}

Segundo Palmonari e Cerrato (2011, p. 320-321), a TRS é um modelo integrativo, onde os a priori sociais e a atividade mental individual são mutuamente conectadas. Ou seja, a TRS se fundamenta simultaneamente, nas perspectivas construtivista e interacionista, "centrando-se na descrição dos conteúdos representacionais, bem como no estudo dos processos que determinam a variação dos conteúdos de um grupo social para outro, visando explicar o comportamento social [...]". De acordo com Abric (2003, p.59) uma RS é: "um conjunto organizado de informações, de opiniões, atitudes e crenças a propósito de um dado objeto. Socialmente produzida, ela é fortemente marcada pelos valores correspondentes ao sistema socioideológico e à história do grupo".

Comumente, pela complexidade e multidimensionalidade das RS, faz-se necessária a adoção de uma abordagem multimetodológica que leve em conta o objeto estudado a partir de diferentes perspectivas. Em particular, um estudo das RS baseado na TNC ou abordagem estrutural, considera que os elementos constitutivos de uma representação são hierarquizados, afetados de ponderações diferentes.

A RS é então compreendida como um sistema sociocognitivo que apresenta uma organização específica: um Sistema Central (SC) e um Sistema Periférico (SP). O SC é constituído pelos elementos que mais vão resistir às mudanças. Sendo assim, Abric (1994, p.79) o descreve como "estável, coerente, consensual e historicamente marcado". Sem o (s) elemento (s) do SC existiria uma total desarticulação da estrutura da representação. Enquanto, o SP é constituído de elementos que podem estar mais ou menos próximos dos elementos do SC. Se eles estão mais próximos, desempenham um papel importante na concretização da significação da representação, se estão mais distantes, podem ilustrar,

\footnotetext{
${ }^{2} \mathrm{~A}$ escolha dos professores de matemática brasileiros e franceses encontra-se apresentada na introdução deste trabalho, no que diz respeito ao CAPES-COFECUB.
} 
explicitar ou justificar esta significação. Os elementos periféricos das RS constituem, podemos dizer, a interface entre o SC e a situação concreta na qual se elabora ou funciona a representação.

O estudo da estrutura das RS envolve três etapas (ABRIC, 1994): 1.0 levantamento do conteúdo; 2. O estudo das relações entre os elementos, de sua importância relativa e de sua hierarquia e 3. A determinação e controle do NC.

Em nossa pesquisa, para o levantamento do conteúdo das RS contamos com a colaboração de 126 professores de matemática brasileiros (PMB) e 126 professores de matemática franceses (PMF), atuantes no Ensino Fundamental (EF) e no Ensino Médio (EM). Nesta etapa, cada professor (a) foi solicitado a responder um Teste de Associação Livre de Palavras (TALP) no qual deveriam indicar seis palavras ou expressões que lhes viessem à mente quando pensassem em "competência para ensinar". O acesso a estes professores ocorreu em encontros de formação continuada promovidos pela Secretaria Estadual de Educação de Pernambuco e pelo Institut Français de l'Education.

No estudo das relações entre os elementos, de sua importância e hierarquia, foi realizado um Teste de Hierarquização (TH). Para tanto, solicitamos aos mesmos 252 professores (brasileiros e franceses) que escolhessem duas palavras ou expressões que considerassem as mais importantes, dentre as seis, indicadas por eles no TALP.

Para a determinação e controle do SC, devido à falta de acesso aos participantes e ao tempo empreendido na análise dos dados do TALP e TH; delimitamos a amostra de participantes, em outros, 20 professores de matemática brasileiros e 10 professores de matemática franceses. Nesta etapa da pesquisa, os 30 professores responderam a um questionário, onde deveriam selecionar os elementos "totalmente indispensáveis", dentre aqueles considerados os mais importantes nos precedentes TALP e TH. E, na sequência, realizamos uma entrevista, com estes mesmos professores, sobre os já identificados elementos do SC.

Esclarecemos que no processo de análise dos dados obtidos no TALP e no TH, utilizamos o software Trideux ${ }^{3}$ como auxílio no levantamento da frequência dos elementos das RS. Para categorização dos elementos, seguimos as etapas da técnica de análise de conteúdo de Bardin (1997): uma primeira leitura para anotação dos possíveis elementos recorrentes nas informações coletadas; pré-categorização-contagem parcial dos elementos identificados; construção de grades de categorias contendo os temas gerais, palavras e frases relacionadas a esses temas; agrupamento de elementos nas categorias e contagem

\footnotetext{
${ }^{3}$ Fonte: http://cibois.pagesperso-orange.fr/Trideux.html
} 
da frequência final de seus elementos. Para a referida categorização, retomamos a ideia da noção de competência como um conjunto estruturado, holístico e integrado (ver Tópico 2.2). De modo que revisitamos os elementos e as dimensões da competência profissional, que nos pareceram mais frequentes (ver: Tópico 2.2): cognitiva (conhecimentos e capacidades); ético-política (atitudes); afetivo-motivacional (afeições e/ou motivações) e social (qualidades subjetivas e/ou traços da personalidade).

Em particular, em virtude da dimensão cognitiva aparecer com maior frequência, nas RS dos professores investigados; para auxílio na identificação dos tipos de conhecimentos mencionados pelos mesmos, consultamos os estudos de Shulman (2005) que configura os conhecimentos dos docentes em: conhecimento do conteúdo; conhecimento didático geral, conhecimento do currículo, conhecimento didático do conteúdo, conhecimento dos estudantes e de suas características; conhecimento dos contextos educativos, conhecimento dos objetivos, as finalidades e os valores educativos, e de seus fundamentos filosóficos e históricos. Além de Shulman; consultamos a categorização de Magnussom et al. (1999) sobre o Conhecimento Pedagógico do Conteúdo (PCK, da sigla em inglês "Pedagogical Content Knowledge"); isto é, os conhecimentos sobre: as dificuldades dos estudantes; as estratégias de ensino; a avaliação; o contexto e os objetivos e razões do ensino.

Salientamos que, se por um lado, buscamos apreender na dimensão cognitiva, os metaconhecimentos e/ou metacognições ${ }^{4}$ dos professores de matemática, isto é, o dito sobre os conhecimentos que eles pensam ser necessários para ensinar de modo competente; de outro modo, buscamos também identificar elementos relacionados à operacionalidade destes conhecimentos: as capacidades mencionadas pelos professores investigados. Pois, como indica Rabardel (2005), a capacidade de agir está ligada às competências, como recursos potencialmente operativos do sistema cognitivo - que podem ser mobilizados e postos em prática pelos sujeitos - no espaço das situações e das classes de situações em seu domínio de atividade profissional.

Nesta direção, na análise dos dados das entrevistas, buscamos por em relevo, o fato que o SC das RS, aparece como um conjunto de elementos de natureza diferente (normativos ou funcionais). Isto é, ora certos elementos do SC intervêm na formulação de julgamentos e de tomadas de posição, ora na determinação das práticas sociais ligadas ao objeto. Os elementos do SC são, assim, ativados segundo o tipo de relação que o grupo

\footnotetext{
${ }^{4}$ A metacognição entendida como o "conhecimento que o indivíduo tem de seu próprio funcionamento e modo de descrever seus conhecimentos e competências" (LE BOTERF, 1999, p.82) e os metaconhecimentos baseados, essencialmente, na interrogação do sujeito sobre: "o que eu sei?".
} 
considerado entretém com o objeto representado. De tal forma, buscamos identificar os diferentes sentidos atribuídos, a propósito de um mesmo elemento presente no SC das representações dos professores brasileiros e franceses - frente à menção de situações profissionais relacionadas a este, em particular, no ensino de matemática.

\section{AS REPRESENTAÇÕES SOCIAIS DA COMPETÊNCIA PROFISSIONAL DOCENTE DE PROFESSORES DE MATEMÁTICA}

Ao buscarmos identificar à luz da TRS, a dimensão cognitiva da competência profissional docente (mencionada por LE BOTERF, 2011; ALLAL, 2004, entre outros), sublinhamos que: a noção de conhecimento em destaque na TRS se configura como um tipo de conhecimento "sui generis" na interpretação e na leitura do real. Neste sentido, acreditamos que o levantamento dos conhecimentos mencionados pelos professores investigados, nas representações de sua competência profissional, traz à tona os conhecimentos que, de certa forma, guiam a sua prática docente. Bem como, permite um olhar sobre suas metacognições e/ou seus metaconhecimentos. De sorte que, no Quadro 1, podemos então, visualizar os conhecimentos e capacidades presentes no sistema representacional dos professores de matemática sobre sua competência profissional, relacionados à dimensão cognitiva:

Quadro 1 - RS - Dimensão cognitiva da competência profissional docente ${ }^{5}$

\begin{tabular}{|c|c|c|c|c|c|}
\hline \multicolumn{3}{|l|}{ Professores brasileiros } & \multicolumn{3}{|l|}{ Professores franceses } \\
\hline Expressões & $\mathrm{FG}$ & SC & Expressões & $\mathrm{FG}$ & SC \\
\hline Conhecimento matemático & 47 & 23 & Conhecimento didático & 17 & 15 \\
\hline Dominar o saber matemático & 33 & 20 & Conhecimento matemático & 26 & 10 \\
\hline Conhecimento de cultura geral & 23 & 12 & Conhecimento de cultura geral & 18 & 09 \\
\hline Formar-se continuadamente & 27 & 11 & Dominar o saber matemático & 15 & 09 \\
\hline Inovar o ensino de matemática & 24 & 11 & Ter clareza nas explicações & 20 & 08 \\
\hline Conhecimento didático & 15 & 08 & Escutar os estudantes & 19 & 07 \\
\hline Organizar seu trabalho pessoal & 22 & 04 & Inovar o ensino de matemática & 17 & 05 \\
\hline Planejar seu ensino & 15 & 04 & Escolher estratégias de ensino & 10 & 05 \\
\hline Escolher estratégias de ensino & 10 & 04 & Conhecimento pedagógico & 19 & 04 \\
\hline Domínio de si-mesmo & 09 & 04 & Refletir sobre o ensino & 17 & 04 \\
\hline $\begin{array}{l}\text { Conhecimento das estratégias de } \\
\text { ensino }\end{array}$ & 11 & 04 & Formar-se continuadamente & 14 & 04 \\
\hline Gerir o grupo & 11 & 04 & Motivar os estudantes & 14 & 04 \\
\hline & & & Gerir o grupo & 08 & 04 \\
\hline & & & Conhecimento do programa & 08 & 04 \\
\hline & & & Comunicar-se adequadamente & 07 & 04 \\
\hline & & & $\begin{array}{l}\text { Conhecimento das dificuldades } \\
\text { em matem. de seus estudantes }\end{array}$ & 08 & 04 \\
\hline Total & 247 & 109 & Total & 237 & 100 \\
\hline
\end{tabular}

Fonte: autoria própria.

${ }^{5}$ Legenda: $F G$ - frequência geral. SC - frequência dos elementos do SC. 
A parte em destaque no Quadro $1^{6}$, diz respeito ao que se sobressaiu no tratamento estatístico do software Trideux, cujo nível de relevância do conteúdo representacional, tem como parâmetro a frequência igual ou maior que quatro indicações.

Deste modo, sobre a dimensão cognitiva das RS de competência para ensinar de professores de matemática brasileiros e franceses (Quadro 1) foi evidenciado em comum, dentre os elementos mais importantes e indispensáveis (SC), três tipos de conhecimentos: matemático, didático do conteúdo e de cultura geral. Contudo, podemos perceber uma maior relevância dada ao "conhecimento matemático" pelos professores brasileiros; enquanto, entre os professores franceses, isto ocorreu em relação ao "conhecimento didático". De modo periférico, identificamos o conhecimento das estratégias de ensino, posto em evidência apenas pelos professores brasileiros. Enquanto, apenas nas representações dos professores franceses identificamos os conhecimentos: pedagógico; do programa e das dificuldades em matemática de seus estudantes.

No que concerne à menção de capacidades apresentadas (Quadro 1) como as mais importantes e indispensáveis (SC), aquelas identificadas em comum entre professores brasileiros e franceses foram: dominar o saber matemático e inovar o ensino de matemática. Foi apenas presente nas representações dos professores brasileiros: a capacidade de formar-se continuadamente. Enquanto, para os professores franceses se destacaram as capacidades de: ter clareza nas explicações; escutar o estudante e escolher estratégias de ensino. Na periferia das RS, os professores brasileiros e franceses concordaram com a capacidade de "gerir o grupo de estudantes em sala de aula". Porém, apenas entre os professores brasileiros foram mencionadas as capacidades de: organizar seu trabalho pessoal; planejar o ensino; escolher estratégias de ensino e domínio de simesmo. Enquanto, as capacidades mencionadas apenas pelos professores franceses incidiram sobre: refletir sobre o ensino; formar-se continuadamente; comunicar-se adequadamente na forma oral e escrita e motivar os estudantes.

O olhar sobre outra categoria, em que situamos o conteúdo representacional dos professores, diz respeito à dimensão ético-política de sua competência profissional. Sobre esta, pomos em relevo o papel da "atitude", no sentido atribuído por Zarifian (2001), como a maneira pela qual um indivíduo se conduz face à realidade em geral. Como vimos, a dimensão ética da noção de competência profissional é citada por Ramalho et al. (2004); Le Boterf (2011); Rios (2010), destacando-se aspectos referentes aos valores que orientam as decisões, aos modos de agir, aos meios a utilizar para atingir os resultados; à orientação

\footnotetext{
${ }^{6}$ Nos demais quadros, também houve o destaque dos elementos segundo o parâmetro estatístico do Trideux.
} 
da ação fundada nos princípios do respeito, da solidariedade e da justiça, na direção da realização de um bem coletivo, e também à consciência e à definição da participação na construção coletiva da sociedade e ao exercício de direitos e deveres. Nesta direção, apreendemos dentre as RS dos professores as seguintes atitudes:

Quadro 2 - RS - Dimensão ético-política da competência profissional docente ${ }^{7}$

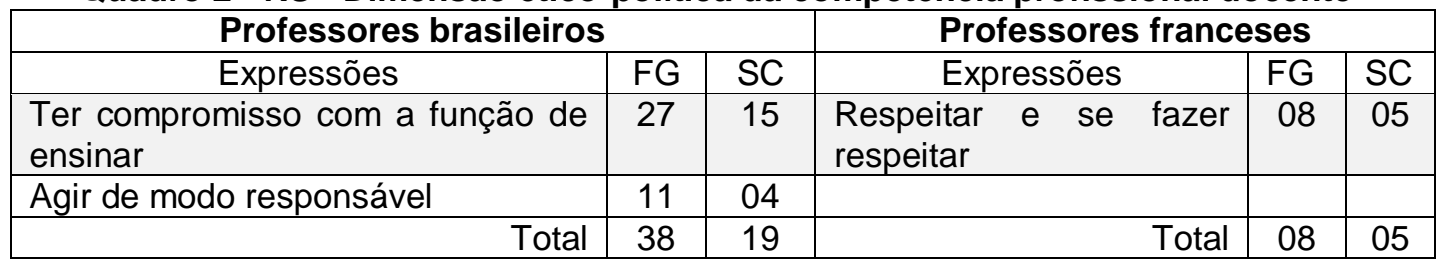

Fonte: autoria própria.

Podemos constatar dentre as representações dos professores brasileiros (Quadro 2) a importância atribuída ao compromisso com a função de ensinar e em menor medida, à responsabilidade do professor. Enquanto, os professores franceses apresentaram a atitude de respeitar e se fazer respeitar como um dos elementos mais importantes e indispensáveis da competência profissional docente.

Complementarmente às dimensões cognitiva e ético-política das RS da competência profissional docente; sublinhamos outra dimensão: a afetivo-motivacional; levando em conta que "toda pessoa é ao cotidiano um sujeito intencional, motivado e com finalidades, logo as atividades e suas ações respondem a normas que os enquadram, a motivos que os impulsionam e a objetivos que derivam mais ou menos contradições" (RABARDEL, 2005, p.12).

Neste sentido, de modo singular, concordamos com Le Boterf (1998), quando este afirma que: para se por em prática as competências não se depende somente de saber agir e de poder agir, ela é fortemente condicionada ao querer agir. Pois, se a competência é bem uma construção pessoal, ela não se obtém por injunção (ordem). Assim pode ser possível obrigar alguém a executar, difícil é obrigar a agir com competência. De sorte que a dimensão afetivo-motivacional, com base nas representações dos professores de matemática investigados (Quadro 3), aparece mais voltada para afeições que variam, sejam pelo gosto à profissão docente, pelo gosto de ensinar, ou mesmo simplesmente, pelo gosto à Matemática.

7 Legenda: FG - frequência geral. SC - frequência dos elementos do Sistema Central. 
Quadro 3 - RS - Dimensão afetivo-motivacional da competência profissional docente ${ }^{8}$

\begin{tabular}{|c|c|c|c|c|c|}
\hline \multicolumn{2}{|c|}{ Professores brasileiros } & \multicolumn{3}{c|}{ Professores franceses } \\
\hline Expressões & FG & SC & Expressões & FG & SC \\
\hline Ter prazer no trabalho & 27 & 15 & Gostar de matemática & 15 & 08 \\
\hline Gostar de matemática & 15 & 08 & Ter prazer no trabalho & 13 & 04 \\
\hline Gostar de ensinar & 22 & 06 & Gostar de ensinar & 06 & 04 \\
\hline \multicolumn{1}{|c|}{ Total } & 64 & 29 & Total & 34 & 16 \\
\hline
\end{tabular}

Fonte: autoria própria.

No Quadro 3, podemos visualizar que foi bem mais frequente no SC das RS dos professores brasileiros, gostar da profissão professor que gostar de matemática, como foi mais enfatizado entre os professores franceses.

Por fim, sobre a dimensão social, uma tendência reconhecida por Zarifian (2001) em torno da noção de competência é a vertente do saber-ser em termos de personalidade e de aptidões. No nosso estudo, através da análise das RS de competência para ensinar, alguns significados relacionados ao « ser um professor de matemática competente» foram sendo desvelados através da menção de algumas qualidades subjetivas e/ou alguns traços da personalidade dos professores, em seu modo de se reconhecerem: "ser professor de matemática", ou simplesmente, podemos dizer no seu "jeito de ser".

Quadro 4 - RS- Dimensão social da competência profissional docente
\begin{tabular}{|l|c|c|c|c|c|}
\hline Professores brasileiros & \multicolumn{3}{|c|}{ Professores franceses } \\
\hline Expressões & FG & SC & Expressões & FG & SC \\
\hline Ser preparado & 34 & 15 & Ser rigoroso & 38 & 15 \\
\hline Ser paciente & 31 & 09 & Ser paciente & 24 & 04 \\
\hline Ser dinâmico & 14 & 06 & Ser curioso & 10 & 04 \\
\hline Ser dedicado & 13 & 04 & & & \\
\hline Total & 92 & 34 & Total & 72 & 23 \\
\hline
\end{tabular}
Fonte: autoria própria.

Sobre os resultados apresentados no Quadro 4, compreendemos, que expressões do tipo "ser preparado", "ser paciente" e "ser dinâmico", entre os elementos do SC das representações dos professores brasileiros e outra distinta - "ser rigoroso", entre as representações dos professores franceses corroboram à identificação de uma dimensão social da competência profissional; voltada para o aspecto relacional do professor com os estudantes, mas também, de modo mais amplo, do professor com o seu trabalho, desenhadas a partir de uma série de construções representacionais no seio do contexto social (Brasil ou França) em que foram sendo engendradas.

Ao passo que entrevistamos os diferentes grupos de professores de matemática, isto nos permitiu identificar, semelhanças e diferenças sobre as conotações dos elementos

${ }^{8}$ Legenda: $F G$ - frequência geral. SC - frequência dos elementos do Sistema Central. 
concernentes às RS da competência profissional docente e o desvelamento de sua aplicação em algumas situações profissionais nos dois campos educativos.

Por exemplo, na dimensão cognitiva - sobre o conhecimento matemático e a capacidade de dominá-lo - foi dito pelos professores brasileiros:

Em minha opinião o conhecimento matemático é essencial e acredito que hoje um dos motivos dos baixos resultados dos estudantes em matemática é a dificuldade que o professor tem com relação ao conhecimento do conteúdo matemático. (PMB16 - do EF com mais de 20 anos de experiência docente).

Como é que o professor vai transmitir aquele conhecimento se ele não tem capacidade nem para si mesmo? Se ele não consegue resolver um problema de matemática, como é que ele vai ensinar? Com certeza, uma coisa está ligada a outra. Porque uma coisa é, assim - eu tenho um conhecimento, outra coisa é eu dominar. Eu dominar é por em prática isso. (PMB20 - do EF com 10 a 20 anos de experiência docente).

Para os mesmos elementos, os professores franceses afirmaram:

Conhecer (matemática) é bom, mas é necessário também dominar. Porque nós mesmos, se não dominarmos, vamos ter dificuldades em ajudar nossos estudantes. É preciso dominar o conhecimento matemático para poder explicá-lo aos estudantes, para ser capaz de compreender o que eles nos dizem e de corrigi-los. (PMF3 - do EM com menos de 10 anos de experiência docente).

$\mathrm{Na}$ dimensão ético-política, dentre os sentidos atribuídos pelos professores brasileiros às atitudes de ter compromisso com a função de ensinar e agir de modo responsável se sobressaiu a postura docente face à responsabilidade de administrar conflitos de ordem social, pedagógica, familiar, de rejeição à matemática, entre outros.

O compromisso e a responsabilidade do professor dentro da sala de aula é triplicada. Porque você tem que ser pai, mãe, pedagogo, psicólogo, amigo, então a responsabilidade é muito grande. (PMB20 - do EF com 10 a 20 anos de experiência docente).

Os professores franceses, ao enfatizarem a atitude de "respeitar e se fazer respeitar", colocaram a ênfase sobre: fazer os estudantes respeitarem as regras da escola, da classe; respeitar aos outros e ele-mesmo o professor, inspirar respeito.

$\mathrm{Na}$ dimensão afetivo-motivacional, um aspecto mencionado por professores brasileiros foi que gostar de ensinar matemática é diferente de gostar de matemática.

Primeiro eu tenho que gostar de matemática, certo? E segundo é eu gostar de ensinar matemática, por quê? Não adianta ser o cara da matemática, saber tudo de matemática, e não saber ensinar. Porque, simplesmente, gostar somente de matemática, ele (o professor) poderia ter feito outra coisa, como engenharia, ou outra área. (PMB8 - do EM com 10 a 20 de anos de experiência docente). 
O prazer de trabalhar como professor se refletiu no gostar dos estudantes, com uma conotação voltada, ora para a boa convivência, ora para o desejo que eles tenham um bom futuro. Foi dito:

Eu sinto prazer em estar com eles (estudantes), até eu me emociono. Apesar de às vezes eles falarem, que eu sou chata, que eu sou isso, que eu sou aquilo, mas eu faço isso para o bem deles. (PMB9 - do EF com menos de 10 anos de experiência docente).

No caso, dos professores de matemática franceses, o "gostar de ensinar" teve uma conotação de projeção do professor em se colocar no lugar do estudante, na busca de entender o que o estudante precisa para aprender.

Tento me colocar no lugar do estudante me dizendo: o que ele gostaria de compreender? Ou, o que ele gostaria de reter do que eu vou the dizer? Então, se podemos dizer isto em uma palavra; isto seria um tipo de projeção. Ou seja, eu me projeto ao lugar do estudante para fazer minha aula. (PMF2 - do EM com 10 a 20 anos de experiência docente).

$\mathrm{Na}$ dimensão social foi bastante evidente entre os professores brasileiros a menção a "ser preparado" com certa relação à adaptação aos imprevistos:

Você tem que estar preparado para o trabalho que você vai fazer, para o tema que você vai discutir; o que você pode utilizar, o que você pensa também que pode acontecer na condução do trabalho. Você tem que estar preparado para fazer modificações, no momento, na sala de aula. (PMB5- do EF e EM com 10 a 20 anos de experiência docente).

No caso dos professores franceses se sobressaiu "ser rigoroso" em relação ao zelo do professor e dos estudantes ao saber matemático.

É necessário sermos bem rigorosos [...]. Não demonstrar nossos pontos fracos aos estudantes, porque se você atraiu a confiança dos estudantes durante o primeiro ou o segundo mês, depois você fica tranquilo o ano todo e aí mesmo quando você erra, os estudantes pensam que foi uma falta de atenção. Se eles não tem confiança?! Se você perdeu isto, todo o tempo, mesmo quando você fizer bem, eles pensarão que você está enganado. (PMF1- do EM com mais de 20 anos de experiência docente).

É necessário ser rigoroso porque eles misturam as noções, aquelas que thes parecem um pouco similares [...]. Logo, ter rigor para tudo, sobre o que escrevemos e sobre tudo o que dizemos. Se nós, de nossa parte, não formos rigorosos, não poderemos pedir aos estudantes que eles sejam; logo, isto é realmente essencial. (PMF7 - do EM com menos de 10 anos de experiência docente). 
De modo geral, os resultados da pesquisa indicam que os professores de matemática brasileiros consideraram, de certo modo, a sua competência profissional docente, baseada no conhecimento matemático, assim como na capacidade de dominá-lo. Além disto, a atitude de ter compromisso com a função de ensinar frente às dificuldades encontradas em sua atuação profissional. Tal fato também com reflexo no prazer em ser professor e estar preparado para os imprevistos em sala de aula. No caso dos professores franceses, além do conhecimento disciplinar e da capacidade de colocá-lo em prática, o conhecimento das dificuldades em matemática dos estudantes condiz a uma correlação maior com o conhecimento didático do conteúdo e com o "rigor" do professor, frente ao ensino e a aprendizagem. Na dimensão ético-política, no contexto francês, percebemos uma ênfase maior sobre o respeito mútuo entre professor e estudantes e o respeito às regras do estabelecimento escolar, que uma preocupação com o "seu futuro", como foi evidente entre os professores brasileiros.

Sobre os resultados supramencionados, sublinhamos que as representações e as práticas sociais se engendram mutuamente. De acordo com Santos (2011, p. 34) "as representações sociais orientam as práticas sociais (na medida em que precedem 0 desenvolvimento da ação). Porém, ela é ao mesmo tempo gerada nas práticas sociais e condicionada à evolução dessas práticas em uma dada sociedade". Assim, entende-se que as RS provêm do senso comum: "das experiências e observações do sujeito (eu vi, eu faço), das comunicações às quais ele é exposto (eu escutei, me disseram) e das crenças que ele mesmo elabora (eu penso, eu acredito)". Deste modo, "qualquer que seja a fonte, isto tem um valor de evidência para os indivíduos" (MOLINER, 1996, p.53-54).

Pelo exposto, no presente estudo, entendemos que o desvelamento pelos próprios professores de sua competência profissional, também traz à tona a função identitária das RS. Pois, o sujeito que compartilha uma RS com um determinado grupo, sente-se como pertencente a este grupo e não a outro (ABRIC, 1994). Assim, longe de esgotarmos o debate sobre a competência profissional docente, cremos que resta em aberto 0 esclarecimento do que a distingue dos demais grupos profissionais - como um exercício de (re) construção identitária do que é ser professor (sobretudo, no contexto nacional), seja de matemática ou de outra área de atuação.

\section{CONSIDERAÇÕES FINAIS}

O presente trabalho teve por objetivo apresentar as representações sociais de professores brasileiros e franceses de sua competência profissional docente. Este estudo, 
trata-se de um recorte de uma pesquisa mais ampla, como dissemos no seio de um projeto CAPES-COFECUB. Esclarecemos que não tivemos a intenção de realizar uma investigação de cunho comparativo; mas apenas demonstrarmos que a noção de competência profissional a depender do contexto social onde ela é engendrada adquire significações diversas.

O caminho teórico-metodológico da Teoria das Representações Sociais, permitiu em um primeiro momento, perceber no campo semântico das representações em tela que: em maior medida, os dois grupos de professores de matemática (brasileiros e franceses), associaram à competência profissional docente: diversos tipos de conhecimentos e capacidades (dimensão cognitiva) e diversas qualidades subjetivas e/ou traços da personalidade do professor (dimensão social). Na sequência, em menor medida, constatamos a menção de afeições e motivações (dimensão afetivo-motivacional) e de atitudes (dimensão ético-política).

No processo de análise dos elementos e dimensões supracitadas, podemos dizer que os dados coletados nas entrevistas foi o que nos permitiu, consideravelmente, a validação dos elementos do SC e do SP, quanto a sua visibilidade na prática docente. Pois, apenas a identificação dos elementos centrais e periféricos das RS, não basta para perceber como eles se manifestam na prática docente. Isto requer, necessariamente, 0 levantamento de situações ou família de situações em que eles se aplicam.

Quando um professor de matemática brasileiro, por exemplo, afirma que faz parte de sua competência profissional "ser preparado", vimos como ele se refere a situações diversas: discussão do conteúdo matemático; possíveis imprevistos na sala de aula, entre outros. O que nos remete a Abric (1994, p.31) ao afirmar que o comportamento dos indivíduos ou dos grupos é diretamente determinado pela representação da situação, que por sua vez, relaciona-se ao contexto e a finalidade da situação. De modo que, concordarmos com Jonnaert (2005) sobre a competência ser sempre contextualizada em uma situação precisa e ser sempre dependente da representação que a pessoa ou o grupo de pessoas se faz desta situação.

No limite de nossa pesquisa, esperamos contribuir à construção de uma visão da noção de competência numa perspectiva desmistificadora e mais abrangente. Sobretudo, pela voz dos professores sobre sua (s) própria (s) competência (s) profissional (is). Ademais, que este trabalho possa suscitar novas pesquisas. 


\section{REFERÊNCIAS}

ABRIC, J-C. Méthodes d'étude des représentations sociales. Ramonville Saint-Agne: Éditions Érès, 2003.

ABRIC, J- C. Méthodologie et recueil des representations sociales. In: ABRIC, J- C. (Org.). Pratiques sociales et représentations. Paris: Puf, 1994. p. 59- 82.

ABRIC, J-C. Jeux, conflits et représentations sociales (Thèse d'État, Université de Provence, Aix-en-Provence, France), 1976.

ALLAL. L. Aquisição e avaliação das competências em situação escolar. In: DOLZ. J.; OLLAGNIER, E. O enigma da competência em educação. Porto Alegre: Artmed, 2004, p. $79-96$.

ALMEIDA, L.M. Representações sociais e prática pedagógica no processo de construção identitária. In: SANTOS, M.F.S.; ALMEIDA, L.M. (Orgs). Diálogos com a teoria das representações sociais. Recife: Editora Universitária UFPE/EdUFAL, 2005. p. 161- 200.

BARDIN, L. Análise de conteúdo. Lisboa: Edições 70, 1997.

DELUIZ, N. O modelo das competências profissionais no mundo do trabalho e na educação: implicações para o Currículo. Boletim Técnico do Senac, Rio de Janeiro, v. 27, n. 3, p. 13-25, set/dez 2001. Disponível em:

<http://www.senac.br/BTS/273/boltec273b.htm>. Acesso em: 24 nov. 2013.

DEPRESBITERIS, L. Avaliando competências na escola de alguns ou na escola de todos? Boletim Técnico do Senac. Rio de Janeiro, v. 27, n. 3, p. 36-47, Set/Dez 2001.

FERREIRA, A.B.H. Dicionário da língua portuguesa. 4. ed. Rio de Janeiro, 2002.

FLEURY. M.; FLEURY, A. Construindo o conceito de competência. Revista de

Administração Contemporânea, Rio de janeiro, Edição Especial, v.1, p. 183-196, 2001.

JODELET, D. Representações sociais um domínio em expansão. In: JODELET, D. As representações sociais. Rio de Janeiro: EdUERJ, 2001, p. 17-44.

JONNAERT, P. et al. Contribution critique au développement des programmes d'études : compétences, constructivisme et interdisciplinarité. Revue des Sciences de l'Éducation, Montréal, v. XXX(3), p. 667-696, 2005.

LARROUSE, Ática. Dicionário da língua portuguesa. São Paulo: Ática, 2002. 
LE BOTERF, G. De la compétence à la navigation professionnelle. 2.ed. Paris: Les Editions d'Organisation, 1998.

.L’ingénierie des compétences. 2.ed. Paris: Les Editions d’Organisation, 1999.

.De quel concept de compétences les entreprises et les administrations ont-elles besoin ? In: BOSMAN. C. et al. Quel avenir pour les compétences? Bruxelles: Boeck Université, 2000. p. 15-19.

L'ingénierie et évaluation des compétences. 6.ed. Paris: Les Editions d'Organisation, 2011.

MAGNUSSON, S. et al. Nature, sources, and development of pedagogical content knowledge for science teaching. In: GESS-NEWSOME, N. G. L. J. (Ed.). Examining Pedagogical Content Knowledge. Boston: Kluwer, 1999. p. 95-132.

MANFREDI, S.M. Trabalho, qualificação e competência profissional: das dimensões conceituais e políticas. Educação \& Sociedade, Campinas, v. 19, p. 13-49, set.1999. ISSN 1678-4626.

MARINHO-ARAUJO, C. M.; RABELO, M. L. Avaliação educacional: a abordagem por competências. Avaliação, Campinas; Sorocaba, SP, v. 20, n. 2, p. 443-466, jul. 2015.

MOLINER, P. Images et représentations sociales: de la théorie des représentations à l'étude des images sociales. Paris: PUF, 1996.

MOSCOVICI, S. La psychanalyse, son image et son public. Paris: PUF: 1961.

ORGANIZAÇÃO INTERNACIONAL DO TRABALHO. Certificação e competências profissionais: análise qualitativa do trabalho, avaliação e certificação de competênciasreferenciais metodológicos. Brasília: OIT, 2002.

PALMONARI, A.; CERRATO, J. Representações sociais e psicologia social. In: ALMEIDA, A.; SANTOS, M.; TRINDADE, Z. Teoria das Representações Sociais: 50 anos. Brasília: Technopolitik, 2011. p. 305. 332.

PASTRÉ, P. Champs conceptuels et champs professionnels. In: MERRI, M. (Coord). Activité humaine et conceptualisation: questions à Gérard Vergnaud.Toulouse: Presses Universitaires du Mirail, 2007. p. 79.86.

PERRENOUD, P. L'école saisie par les compétences. In: BOSMAN, C. et al. (Org.). Quel avenir pour les compétences? Bruxelles: De Boeck Université, 2000. p. 21-41. 
PIRES, A. L.O. Educação e formação ao longo da vida: análise crítica dos sistemas e dispositivos de reconhecimento e validação de aprendizagens e de competências. 2002. 646f. Tese (Doutorado em Ciências da Educação) - Faculdade de Ciências e Tecnologia, Universidade Nova de Lisboa, Lisboa, 2002.

RABARDEL, P. Instrument subjectif et développement du pouvoir d'agir. In: RABARDEL, P.; PASTRE, P. Modèles du sujet pour la conception: dialectiques, activités, développement. Toulouse: Octarès, 2005. p. 11-29.

RAMALHO, B. L. et al. Formar o professor profissional: perspectivas e desafios. 2.ed.Porto Alegre: Sulina, 2004.

RAMOS, M. A pedagogia das competências: autonomia ou adaptação? 4.ed. São Paulo: Cortez, 2011.

REY, A. (Dir.). Le Robert micro: dicionário da língua francesa. Paris: Poche, 2006.

RIOS, T. Competência ou competências: o novo e original na formação de professores. In: ROSA, D. G.; SOUZA, V. C. (Orgs.). Didática e práticas de ensino: interfaces com diferentes saberes e lugares formativos. Rio de Janeiro: DP\&A, 2002, p.154-172.

A construção permanente da competência. In: ROVAI, E. Competência e competências: contribuição crítica ao debate. São Paulo: Cortez: 2010, p. 149-166.

ROPÉ, F.; TANGUY, L. Introduction. In: ROPÉ, F.; TANGUY, L. (Orgs). Savoirs e compétences: de l'usage de ces notions dans l'école et l'entreprise. 5. ed. Paris: L'Harmattan, 1994, p. 13-22.

ROVAI, E. Educação profissional: a formação do cidadão produtivo e transformativo. In: ROVAI, E. (Org.). Competência e competências: contribuição crítica ao debate. São Paulo: Cortez: 2010, p. 21-67.

SACRISTÁN, G. Consciência e ação sobre a prática como libertação profissional dos professores. In: NÓVOA, A. (org.). Profissão professor. Porto: Porto, 1999.

SHULMAN, L. Conocimiento y enseñanza: fundamentos de la nueva reforma. Profesorado. Revista de currículum y formación del professorado, Granada, v. 9, p.130, 2005.

SANTOS, M.F.S. A teoria das representações sociais. In: SANTOS, M.F.S.; ALMEIDA, L.M. (Orgs). Diálogos com a teoria das representações sociais. Recife: Editora Universitária UFPE/EdUFAL, 2005. p. 13-38. 
SOUZA, C.; PESTANA, M. A polissemia da noção de competência no campo da educação. Revista de Educação Pública, Cuiabá, v.18, n.36, p. 133-151, jan./abr. 2009.

TARDIF, J. L'évaluation des compétences. Quebec: Chenalière Éducation, 2006.

VERGNAUD, G. La théorie des champs conceptuels. Recherches en Didactique des Mathématiques, Paris, v. 10, n.23, p. 133-170, 1990.

WITTORSKI, R. De la fabrication des compétences. Éducation Permanente, Arcueil, n.135.2, p.57-69, 1998.

. Les rapports théoriques-pratique dans la conduite des dispositifs d'analyse de pratiques. Éducation Permanente, Arcueil, n.160.3, p. 1-9, 2004.

ZARIFIAN, P. Objetivo competência: por uma nova lógica. São Paulo: Atlas, 2001. 